\title{
Spectrum of Coronary Angiographic Findings in Potential Renal Transplant Recipients in a Tertiary Care Center of Nepal
}

This article was published in the following Dove Press journal: Transplant Research and Risk Management

\author{
Vijay Yadav \\ Sunil Chandra Jha \\ Ratna Mani Gajurel (D) \\ Chandra Mani Poudel \\ Ravi Sahi (iD \\ Manju Sharma \\ Suman Adhikari
}

Department of Cardiology, Manmohan Cardiothoracic Vascular and Transplant Centre, Kathmandu, Nepal
Correspondence: Vijay Yadav Department of Cardiology, Manmohan Cardiothoracic Vascular and Transplant Centre, Kathmandu, Nepal

Tel +977-985I20II26

Email vjmedicine45I@gmail.com
Background: Studies emphasizing the prevalence of coronary artery disease (CAD) and the diversity of coronary lesions among asymptomatic renal transplant recipients (RTRs) are few and far between in Nepal.

Methods: In this cross-sectional observational study, a cohort of potential RTRs who were subjected to coronary angiography $(\mathrm{CAG})$ as a part of both routine pre-op evaluation and therapeutic modality were enrolled and the spectrum of coronary angiographic lesions was reported. Significant CAD was defined by angiography as $\geq 70 \%$ stenosis. Percutaneous coronary intervention (PCI) was done for significant lesions.

Results: A total of 60 patients (mean age: $53.7 \pm 7.2$ years, 43 males and 17 females) formed the subjects of the study. Diabetes was the commonest cause of ESRD (61.7\%) with the mean duration of ESRD being $4.3 \pm 2.2$ years. Of the patients, $86.7 \%$ were routinely subjected to $\mathrm{CAG}$ and the remaining $13.3 \%$ presented with acute coronary syndrome. The right femoral artery was the most common access vessel (81.7\%). CAD was present in 30/60 patients $(50 \%)$. The left anterior descending artery was the most common culprit vessel (46.7\%), followed by the left circumflex artery (38.3\%). Among the routine CAG group, $42.3 \%$ had some form of $\mathrm{CAD}$, the highest proportion of which was triple vessel disease (23.3\%). Both double vessel disease and triple vessel disease were found to be highly prevalent in patients with hyperlipidemia, diabetes, and in smokers. The angiographic lesions were predominantly of discrete (41\%), diffuse (35.9\%), and eccentric $(46.2 \%)$ types, had tandem arrangement (58.9\%) with moderate angulation $(56.4 \%)$, and were irregular $(58.9 \%)$ in contour. A total of 3 ostial (7.7\%) and 9 calcified (23.1\%) lesions were found to be present. Chronic total occlusion and bifurcation lesions were observed in $4(10.3 \%)$ and 5 $(12.8 \%)$ cases, respectively. Six (15.4\%) patients had well-developed collaterals. Twenty-one $(53.8 \%)$ patients underwent PCI and $3(7.7 \%)$ patients underwent coronary artery bypass surgery. Type B2 was the most common lesion (46.2\%).

Conclusion: Asymptomatic ESRD patients on the renal transplant list were found to have a high prevalence of CAD. CAG can be an efficient screening alternative for the detection of significant CAD among these patients.

Keywords: coronary angiography, coronary artery disease, triple vessel disease, end-stage renal disease, kidney transplant

\section{Introduction}

Chronic kidney disease (CKD), a major health problem worldwide, is an independent risk factor for coronary artery disease (CAD) which, in turn, is the leading cause of morbidity and mortality in patients with CKD. ${ }^{1}$ The prevalence of ischemic heart 
disease at the time of starting dialysis is variable across different countries, ranging from $28 \%$ to $41 \%$. $^{2}$ Among patients who receive renal replacement therapy (RRT), cardiac death accounts for almost $40-50 \%$ of total deaths - out of which $10 \%$ to $20 \%$ are due to acute coronary events. ${ }^{3,4}$ Renal transplantation is the treatment of choice for patients with end-stage renal disease in terms of prolonging survival and improving quality of life. The risk of a major adverse cardiac event (MACE) is found to be relatively constant while on the waiting list, then rises markedly in the early post-transplant period, and declines at a slower rate thereafter, ${ }^{5}$ which mandates the screening for CAD as a part of the pre-transplant evaluation - not only to assess pre-operative risk but also to stratify cardiovascular risk into early years of transplantation and to preemptively identify vascular lesions amenable to revascularization. The ideal screening strategies for CAD in the potential renal recipient remain controversial and vary among different transplant societies. Some centers have adopted a risk-stratified approach using non-invasive techniques followed by coronary angiography (CAG) for high-risk patients only, while others offer coronary angiography to all potential transplant recipients undergoing evaluation. ${ }^{6,7}$ Although it is widely accepted that percutaneous coronary intervention (PCI) does not confer a mortality benefit in asymptomatic or stable coronary artery disease patients - which is present in 37$58 \%$ of asymptomatic ESRD patients, ${ }^{8-10}$ many of these studies have largely excluded patients with renal failure and hence the findings cannot be applied to them. CAG appears to be a better option in these patients because of the lower sensitivity and specificity of non-invasive tests compared to the general population. ${ }^{11}$ We aimed to find out the prevalence of CAD in CKD patients awaiting transplantation and to stratify different types of angiographic lesions in them.

\section{Methods}

This is a single-centered, cross-sectional, observational study carried out at the Department of Cardiology of the Manmohan Cardiothoracic Vascular and Transplant Center (MCVTC), Institute of Medicine (IOM), which is one of the leading referral tertiary care centers of Nepal. All patients of CKD under maintenance hemodialysis, aged $>40$ years, irrespective of cardiac risk status, with or without diabetes, a history of $\mathrm{CAD}$, prior $\mathrm{PCI}$, prior $\mathrm{CABG}$, or prior renal transplantation, who were candidates for renal transplantation, and who provided written consent for the study were subjected to coronary angiography between August 4, 2019 to February 20, 2020. Data were collected through a pro forma questionnaire method after approval was received from the Institutional Review Board (IRB) of IOM. This study was conducted in accordance with the Declaration of Helsinki.

In addition to demographic data, we assessed the presence of traditional risk factors of CAD (hypertension, hyperlipidemia, diabetes, and smoking), left ventricular ejection fraction by echocardiography, and indication of coronary angiography. We also determined the primary cause of kidney disease, the total vintage of ESRD, and the total vintage of dialysis in each subject cohort. The Cockroft-Gault equation was used to calculate the creatinine clearance.

Prior to CAG, all patients received oral $\mathrm{N}$-acetylcysteine (1200 mg twice daily on days $-1,0$ and +1 ). They did not fast for fluids. Adequate hydration was achieved with the use of intravenous saline from arrival until discharge if patients had no clinical signs of fluid overload. Since all subject cohorts were on maintenance hemodialysis, provision was made to schedule the hemodialysis on the following day of CAG. Coronary angiographies with or without PCIs were performed by six operators through the femoral, radial, or anatomical snuff box access. The iso-osmolar iodinated contrast was used and every effort was made to administer the least possible amount of the contrast. All angiograms were reviewed by two interventional cardiologists and were visually quantified in the coronary angiography PHILIPS XCELERA Viewer. The result was assessed as minor CAD (all lesions $<50 \%$ ); one-vessel, two-vessel, or three-vessel disease (stenosis $>50 \%$ in one, two, or three major vessels, respectively); and left main disease (stenosis $\geq 50 \%$ in the left main). The coronary angiographic lesions with a stenosis of $\geq 70 \%$ were considered significant and were amenable for percutaneous intervention. The length, eccentricity, arrangement, contour, and accessibility of the angiographic lesions were noted. Lesion calcification was classified as none/mild (no or mild radiopacities visualized only during the cardiac cycle) or moderate/severe (dense radiopacities visualized in a still frame before contrast injection in at least one of the significant lesions of the patient). The ostial lesions and chronic total occlusions (CTO) were also taken into account. Bifurcation lesion and the presence of collaterals were graded as per Medina and Rentrop classifications, respectively. All coronary lesions were described as per the joint American Heart Association/American College of Cardiology (AHA/ACC) task force classification system, namely: Type A, B1, B2, and $\mathrm{C}$. 
We finally reviewed the plan made after coronary angiography (medical therapy, $\mathrm{PCI}$, or $\mathrm{CABG}$ ). The mode of revascularization was decided as per the established clinical indications and also in accordance with the patient's preference. PCI was considered successful with the attainment of TIMI 3 flow.

\section{Results}

\section{Baseline Clinical, Laboratory and Transplantation Characteristics}

A total of 60 subject cohorts underwent coronary angiography at MCVTC during the study period. Out of these, 43 $(71.7 \%)$ were male and $17(28.3 \%)$ were female. The mean age of the patients was $53.7 \pm 7.2$ years. Diabetic nephropathy was the most common cause of ESRD (61.7\%). The mean vintage of ESRD was $4.3 \pm 2.2$ years with a mean eGFR of $9.33 \pm 3.18 \mathrm{~mL} / \mathrm{min} / \mathrm{m}^{2}$. The mean duration of dialysis was $2.1 \pm 1.7$ years. The above information is shown in Table 1.

\section{Coronary Angiographic Characteristics}

Most of the study patients $(86.7 \%)$ were routinely subjected to CAG as a part of the pre-operative cardiac evaluation and 8 patients (13.3\%) had suffered from an acute coronary event out of which 7 patients were diagnosed to have non-ST elevation MI (NSTEMI) and 1 patient had suffered from ST elevation MI (STEMI). The majority of coronary angiographies were performed through the right femoral artery $(81.7 \%)$. The baseline coronary angiography established the diagnosis of coronary artery disease in $30(50 \%)$ patients with a higher incidence of triple vessel disease (23.3\%) and single vessel disease $(16.7 \%)$ in them. The minor coronary artery disease was present in $15 \%$ of patients. The most common culprit vessel was the left anterior descending (LAD) artery $(46.7 \%)$ followed by the left circumflex (LCx) artery $(38.3 \%)$. The right coronary artery (RCA) had the highest median obstruction ( $90 \%$ stenosis). Table 2 encapsulates the information provided above.

\section{Characteristics of Coronary Angiographic Lesions Observed in the Study Population That Had Some Form of CAD $(n=39)$}

The coronary angiographic lesions were most commonly found to be discrete (41\%) followed by diffuse (35.9\%) in length and were mostly eccentric (46.2\%); tandemly arranged (58.9\%) with moderate angulation (56.4\%);
Table I Baseline Clinical, Laboratory, and Transplantation Characteristics of the Study Participants $(n=60)$

\begin{tabular}{|l|l|}
\hline Variables & Mean \pm SD or N (\%) \\
\hline Age (years) & $53.7 \pm 7.2$ \\
Gender (M/F) & $43(71.7) / 17(28.3)$ \\
\hline Ethnicity & \\
Brahmin & $32(53.3)$ \\
Chhetri & $9(15.0)$ \\
Mongolian & $13(21.7)$ \\
Newar & $6(10.0)$ \\
BMI (kg/m $\left.{ }^{2}\right)$ & $23.9 \pm 3.1$ \\
\hline Traditional risk factors & \\
Hyperlipidemia & $23(38.3)$ \\
Diabetes mellitus & $35(58.3)$ \\
Smoking & $35(58.3)$ \\
Hypertension & $60(100.0)$ \\
\hline Prior CAD & $3(5.0)$ \\
Prior PCl & $2(3.3)$ \\
LVEF (\%) & $51.2 \pm 12.9$ \\
\hline Cause of CKD & \\
CGN & $4(6.7)$ \\
DM & $37(61.7)$ \\
HTN & $18(30.0)$ \\
CrGN & $1(1.7)$ \\
\hline Prior renal transplantation & $1(1.7)$ \\
Total years of ESRD & $4.3 \pm 2.2$ \\
Total years on dialysis & $2.1 \pm 1.7$ \\
eGFR (mL/min/m $\left.{ }^{2}\right)$ & $9.33 \pm 3.18$ \\
HbAlc (\%) & $7.54 \pm 2.39$ \\
\hline
\end{tabular}

Abbreviations: $\mathrm{BMI}$, body mass index; $\mathrm{CAD}$, coronary artery disease; $\mathrm{PCl}$, percutaneous coronary intervention; LVEF, left ventricular ejection fraction; ESRD, end stage renal disease; eGFR, estimated glomerular filtration rate; $\mathrm{HbAlc}$, glycosylated hemoglobin.

irregular in contour $(58.9 \%)$ and had moderate tortuosity of the proximal segment (33.3\%). Mild to moderate calcified lesions were present in $23.1 \%$ of patients. Complete total occlusion (CTO) and ostial lesions were present in $10.3 \%$ and $7.7 \%$ of patients, respectively. The bifurcation lesion was present in $12.8 \%$ of patients and $15.4 \%$ had well-developed collaterals. To summate, type B2 was the most common coronary angiographic lesion (46.2\%) identified in the potential RTRs.

Following CAG, out of 39 patients with CAD, $53.8 \%$ of renal recipients underwent successful percutaneous transluminal coronary angioplasty (PTCA) to the respective culprit vessels, $23.1 \%$ were advised to have optimal medical therapy, and $7.7 \%$ were subjected to coronary artery bypass surgery (CABG). Among subjects who underwent PTCA, a 
Table 2 Coronary Angiographic Characteristics in the Study Population $(n=60)$

\begin{tabular}{|l|l|}
\hline Variables & N (\%) \\
\hline Indication for CAG & $52(86.7)$ \\
Routine & $8(13.3)$ \\
\hline Acute coronary syndrome & \\
\hline Vascular access & $49(81.7)$ \\
Femoral & $7(11.7)$ \\
Radial & $4(6.7)$ \\
RASB & \\
\hline Results of CAG & $21(35.0)$ \\
Normal & $9(15.0)$ \\
Minor CAD & $10(16.7)$ \\
Single-vessel disease & $6(10.0)$ \\
Dual-vessel disease & $14(23.3)$ \\
Triple-vessel disease & \\
\hline Culprit vessel & $28(46.7)$ \\
LAD & $23(38.3)$ \\
LCX & $20(33.3)$ \\
RCA & $80(40-95 \%)$ \\
\hline Median \% obstruction (range) & $80(40-100 \%)$ \\
LAD & $90(40-100 \%)$ \\
LCX & \\
RCA & \\
\hline
\end{tabular}

Abbreviation: CAG, coronary angiogram.

total of 43 drug-eluting stents were deployed - 18 in LAD, 13 in RCA, and 12 in LCx. Table 3 summarizes the above information.

Among the routine CAG group, $42.3 \%$ had some form of CAD, the highest proportion of which being TVD. The B2-type lesion was the most predominant accounting for more than half $(55.5 \%)$ of these coronary lesions. Figure 1 shows the distribution of CAG results by indication.

\section{Multivariate Analysis}

The severity of CAD, as assessed by the number of vessels involved and degree of obstruction ( $\%$ obstruction), was found to be significantly associated with the traditional risk factors (hyperlipidemia, diabetes, smoking, and hypertension). DVD and TVD were also found to be highly prevalent in smokers $(p<0.001)$, patients with hyperlipidemia $(p<0.05)$, and diabetes mellitus $(p<0.05)$. However, there was no significant correlation of severity of CAD with age, gender, ethnicity, BMI, cause of ESRD, total years of ESRD, total years on dialysis, and eGFR. The degree of coronary artery occlusion had a good positive correlation with HbA1c (Spearman's rho $=0.505, p<0.05$ ).
Similarly, B2 and C-type lesions (that indicate moderate to low success rate of the angiographic procedure) were significantly associated with male gender $(p=0.036)$, diabetic patients $(p=0.001)$ but not with smoking $(p=0.383)$ and hyperlipidemia $(p=0.142)$.

\section{Discussion}

This observational study is the first of its kind in Nepal aimed to investigate the spectrum and morphology of coronary angiographic lesions in potential renal transplant recipients. Renal transplantation offers a greater survival advantage over other forms of renal replacement therapy. ${ }^{12}$ As cardiovascular disease is the most common cause of post-transplant morbidity and mortality, ${ }^{13}$ it has become a therapeutic option to perform coronary angiography in all high-risk potential transplant recipients with a view to revascularization of significant $\mathrm{CAD}$ before transplantation in order to minimize perioperative cardiac events and reduce long-term cardiac morbidity. This study is unique in the sense that all of the potential renal transplant recipients fulfilling the inclusion criteria were subjected to coronary angiography irrespective of symptoms and risk factors as a part of the pre-operative cardiac evaluation.

The age and sex distribution of our study population and higher incidence of CAD in male patients in all age groups were comparable with earlier studies. ${ }^{14,15}$ The traditional risk factors for CAD (hypertension, diabetes, dyslipidemia, and smoking history) were also observed to be highly prevalent. A significant proportion (58.3\%) of the patients were diabetic, with diabetic nephropathy being the most common cause of CKD in our subject cohorts, which was consistent with the findings of earlier similar studies. ${ }^{7,16}$

The incidence of CAD in our study was $50 \%$, which is similar to a study done by Ohtake et al. ${ }^{17}$ There was a higher incidence of triple vessel disease $(23.3 \%)$ followed by single vessel disease $(16.7 \%)$ in our study. The prevalence of TVD in these groups of patients has been variable, reported as high as $76 \%{ }^{18,19}$ In our study, type B2 $(46.2 \%)$ was the most common coronary lesion identified. In contrast, an earlier study showed that type $C(66.9 \%)$ was the most common lesion identified in CKD patients under hemodialysis and that the low eGFR was observed to be a stronger marker of severity and complexity of angiographic lesions in $\mathrm{CAD} .{ }^{20} \mathrm{But}$, as our study included all patients with eGFR $<15 \mathrm{~mL} / \mathrm{min} / \mathrm{m}^{2}$, where an admixture of coronaries was involved, establishment of the correlation between low eGFR and the severity of CAD was not feasible. 
Table 3 Characteristics of Angiographic Lesions Observed in the Study Population That Had Some Form of CAD $(n=39)$

\begin{tabular}{|c|c|}
\hline Angiographic Lesion Characteristics & $\mathbf{N}(\%)$ \\
\hline \multicolumn{2}{|l|}{ Lesion length } \\
\hline Discrete & $17(41.0)$ \\
\hline Tubular & $13(33.3)$ \\
\hline Diffuse & 14 (35.9) \\
\hline Mixed & $13(33.3)$ \\
\hline \multicolumn{2}{|l|}{ Eccentricity } \\
\hline Eccentric & $18(46.2)$ \\
\hline Concentric & $16(41.0)$ \\
\hline Mixed & I (2.6) \\
\hline \multicolumn{2}{|l|}{ Arrangement of lesion } \\
\hline Tandem & $23(58.9)$ \\
\hline Sequential & $19(48.7)$ \\
\hline Mixed & $10(25.6)$ \\
\hline \multicolumn{2}{|l|}{ Angulation of lesion } \\
\hline Mild & $14(35.9)$ \\
\hline Moderate & $22(56.4)$ \\
\hline \multicolumn{2}{|l|}{ Contour } \\
\hline Smooth & $13(33.3)$ \\
\hline Irregular & $23(58.9)$ \\
\hline Ulcerated & $2(5.2)^{\#}$ \\
\hline \multicolumn{2}{|l|}{ Accessibility } \\
\hline Mild & $12(30.8)$ \\
\hline Moderate & $13(33.3)$ \\
\hline None & $2(5.2)$ \\
\hline Calcification & $9(23.1)$ \\
\hline Mild & 6 \\
\hline Moderate & 3 \\
\hline Thrombus & I (2.6) \\
\hline Ostial lesion & $3(7.7)$ \\
\hline Complete total occlusion & $4(10.3)$ \\
\hline Bifurcation lesion & $5(12.8)$ \\
\hline Medina class & 2 \\
\hline $0,1,1$ & 2 \\
\hline $\mathrm{I}, 0, \mathrm{I}$ & 1 \\
\hline \multicolumn{2}{|l|}{ I,I,I } \\
\hline Collateral channels & $6(I 5.4)$ \\
\hline Rentrop class & 2 \\
\hline I & 4 \\
\hline \multicolumn{2}{|l|}{2} \\
\hline \multicolumn{2}{|l|}{ Lesion type } \\
\hline A & $16(41.0)$ \\
\hline $\mathrm{BI}$ & $2(5.2)$ \\
\hline B2 & $18(46.2)$ \\
\hline $\mathrm{C}$ & $3(7.7)$ \\
\hline
\end{tabular}

(Continued)
Table 3 (Continued).

\begin{tabular}{|l|l|}
\hline Angiographic Lesion Characteristics & N (\%) \\
\hline Consultation after angiography* & \\
Medical & $13(33.3)$ \\
PTCA & $2 I(53.8)$ \\
POBA & $\mathrm{I}(2.6)$ \\
PPCI & $\mathrm{I}(2.6)$ \\
CABG & $3(7.7)$ \\
Successful/Attempted PCI & $30 / 0(100)$ \\
\hline
\end{tabular}

Notes: "Both observed in RCA. *Out of 39 patients with CAD. 'FFR guided PTCA was done in I patient.

The utility of non-invasive modalities for predicting CAD in RTRs has been explored, but the results are unsatisfactory. The sensitivity of stress electrocardiograms has been reported as up to $35 \% .^{21}$ Given the high incidence of LV hypertrophy, resting ST-T abnormalities on ECG, poor exercise tolerance, high resting heart rate, blunted heart rate, and blood pressure response to exercise due to autonomic dysfunction in diabetics (as most of them are), exercise electrocardiography is not recommended in this population. ${ }^{22}$ Likewise, due to a higher incidence of coronary artery calcification in ESRD, routine testing with coronary computed tomography angiography (CCTA) as a part of screening for CAD is not recommended. ${ }^{23}$ Similarly, dobutamine stress echocardiography (DSE) and cardiac single photon emission computed tomography (SPECT) scans were not proven to be excellent alternatives; rather, the stress imaging had an unacceptably high rate of false positives to complicate matters. ${ }^{11,24,25}$ It is for the aforementioned reasons that

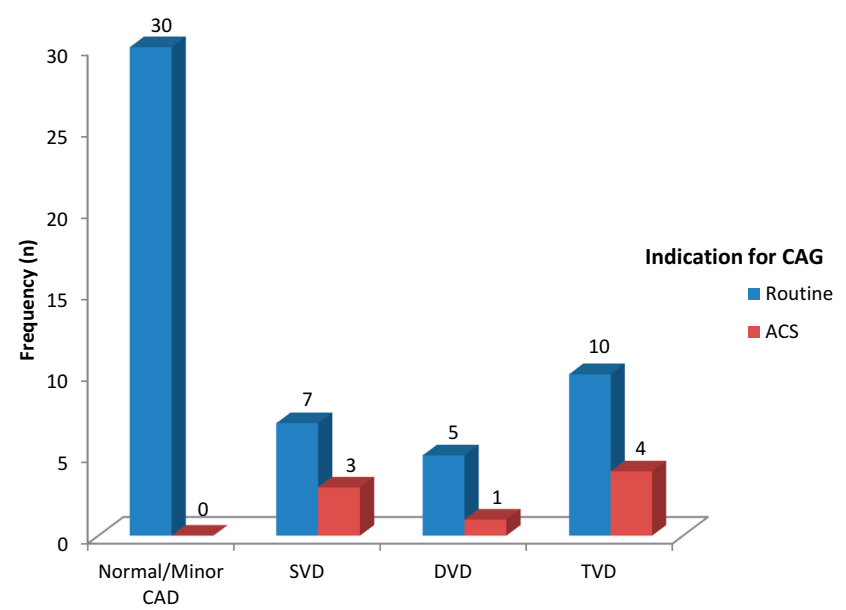

Figure I Distribution of CAG results by indication (routine $=52$ and acute coronary syndrome $=8$ ). 
CAG is the best predictor of cardiac events in renal transplant candidates when compared to non-invasive testing. ${ }^{26}$

There are discrepancies between various national organizations regarding appropriate pre-transplant workup and the exact protocol for cardiac testing in ESRD patients on the transplant list. The National Kidney Foundation ${ }^{27}$ and the American Society of Transplantation ${ }^{28}$ recommend an aggressive approach to screening pre-renal transplant patients with invasive studies, whereas the American College of Cardiology/American Heart Association (ACC/ AHA) considers no further testing in asymptomatic patients undergoing non-cardiac surgery with a functional capacity of $>4$ METs regardless of the risk factors for $\mathrm{CAD}^{29}{ }^{29} \mathrm{In}$ contrast to Nepal, the RTRs are subjected to CAG only if they have symptoms suggestive of coronary ischemia or if they have a high-risk feature like the presence of diabetes. It is the authors' understanding that a non-aggressive approach might not adequately estimate cardiac risk in the ESRD population as these patients can have significant CAD in the absence of symptoms. Moreover, these guidelines specifically focus on assessing short-term cardiac risk prior to elective surgery, whereas in ESRD patients on the transplant list long-term cardiac risks must also be considered as donor organ availability and the actual time of transplant can take anywhere from months to years.

Our study has reported the prevalence of significant CAD to be $42.3 \%$ in routinely subjected asymptomatic potential RTRs, predominantly in the form of TVD. The burden is higher than our expectations and it has been shown elsewhere too. ${ }^{7}$ Coronary angiograms are underused in patients with CKD. ${ }^{30,31}$ A study done by Lentine et $\mathrm{al}^{32}$ has also advocated for routine screening of CAD even in asymptomatic ESRD patients if they are a potential renal recipient. As the risk of major adverse cardiac events rises markedly in the early post-transplant period, ${ }^{5}$ screening for CAD is recommended as a part of the pretransplant evaluation - not only to assess pre-operative risk but also to stratify cardiovascular risk into early years of transplantation and to preemptively identify vascular lesions amenable to revascularization. Benefits of early invasive strategy have been observed, such as a decrease in the risk of hospitalization, death, and re-infarction in CKD patients, particularly those who suffer an acute coronary event. ${ }^{33}$

However, CAG has been underused in patients with $\mathrm{CKD}^{30,31}$ mainly because of the concerns regarding the development of contrast-induced nephropathy and cholesterol embolism. The other interfering factors for CAG in
Nepal would be illiteracy, poverty and cost issues, and inability to correctly decide whether to advance to the procedure in spite of adequate counseling. Cardiovascular complications are still the leading cause affecting the longterm survival of RTRs after surgery. ${ }^{34}$ There are multiple studies that suggest the association of pre-emptive CAG and intervention with low cardiac morbidity and mortality in CKD patients that subsequently got transplanted or are on the transplant waiting list. ${ }^{7,35}$ Similarly, in a recent meta-analysis of 38 nonrandomized studies with 85,731 patients with CKD, a $27 \%$ lower mortality was observed with coronary revascularization when compared with no revascularization. ${ }^{36}$

However, patients with CKD have been under-represented in contemporary stable ischemic heart disease trials comparing revascularization with medical therapy, such as BARI 2D, COURAGE, and FAME 2 trials. The above trials failed to show that an initial invasive strategy reduced the risk of death or myocardial infarction (MI) when compared with an initial conservative strategy of medical therapy alone. As a result, the best treatment approaches for patients with kidney disease remain shrouded by uncertainty. One of the most recently conducted trials, of 777 patients with moderate to severe ischemia and advanced CKD, concluded that routine invasive therapy failed to reduce the incidence of death or myocardial infarction compared with optimum medical therapy. ${ }^{37}$

It is worth highlighting that though the benefits of coronary revascularization in CKD patients are sparse, the clinical situation would be different when the same cohort is being evaluated for renal transplantation. The pre-existing comorbidities could adversely affect the short and long-term outcomes in the post-transplant period. Firstly, the presence of untreated pre-existing CAD might increase the probability of developing perioperative myocardial infarction immediately after surgery. Secondly, the continual use of immunosuppressive therapy after a successful renal transplant would render the patient susceptible to acquiring different CVDs that would eventually cause late allograft loss, thereby decreasing the life expectancy of renal transplant recipients. The incidence of cardiovascular risk factors such as hypertension, dyslipidemia, endothelial dysfunction, and impairment of fibrinolysis substantially increases in RTRs receiving immunosuppressive therapy. ${ }^{38,39}$ Pre-existing CAD has been found to be a strong independent predictor of patient mortality post-transplant; ${ }^{40}$ therefore, CAG could be performed prior to transplantation so that pre-emptive revascularization 
could be done in the infarct-related artery to reduce cardiac morbidity and mortality in the long run. Putting things in order for renal transplantation is physically, mentally, and economically challenging. The course that begins with subjecting the RTRs to multiple pre-transplant workup investigations, matching the correct donors, and having a command on the operative as well as post-operative wealth for costly immunosuppressive drugs would be highly aided by properly addressing pre-existing CAD in the pre-transplant period. Because the study site is one of the most trustworthy health centers of Nepal which is capable of skillfully dealing with both cardiac and transplant issues, the authors suggest that incorporating routine $\mathrm{CAG}$ during transplant workup at the center that could have a role in improving the post-transplant outcomes.

Our study has several limitations. First, the SYNTAX score was not calculated to define the angiographic severity of the coronary lesions. Second, the patients were not followed for the development of contrast-induced nephropathy and for the short-term outcomes following revascularization. Third, it is a single-center study with a small sample size.

\section{Conclusion}

Coronary artery disease is very common among asymptomatic renal transplant recipients who undergo coronary angiography as part of routine pre-operative cardiac evaluation. Since there are conflicting and limited data regarding identification of patients who will benefit from revascularization, our cardiac assessment during the pretransplant period could be considered aggressive and was performed only to fully optimize the cardiac status of a patient in preparation for transplantation. Long-term followup studies are required further to assess the clinical outcomes in these patients.

\section{Disclosure}

The authors report no conflicts of interest in this work.

\section{References}

1. Cai Q, Mukku VK, Ahmad M. Coronary artery disease in patients with chronic kidney disease: a clinical update. Curr Cardiol Rev. 2013;9 (4):331-339. doi:10.2174/1573403X10666140214122234

2. Parfrey PS, Foley RN. The clinical epidemiology of cardiac disease in chronic renal failure. Clin J Am Soc Nephrol. 1999;10(7):1606-1615.

3. Herzog CA, Ma JZ, Collins AJ. Poor long-term survival after acute myocardial infarction among patients on long-term dialysis. $N$ Engl J Med. 1998;339(12):799-805. doi:10.1056/NEJM199809173391203
4. Collins AJ, Foley RN, Herzog C, et al. US Renal Data System 2012 annual data report. Am J Kidney Dis. 2013;61(1):E1-E459. doi:10.1053/j.ajkd.2012.11.031

5. Hart A, Weir MR, Kasiske BL. Cardiovascular risk assessment in kidney transplantation. Kidney Int. 2015;87(3):527-534. doi:10.1038/ ki.2014.335

6. Patel R, Mark P, Johnston N, et al. Prognostic value of cardiovascular screening in potential renal transplant recipients: a single-center prospective observational study. Am J Transplant. 2008;8(8):1673-1683. doi:10.1111/j.1600-6143.2008.02281.x

7. Kumar N, Baker CS, Chan K, et al. Cardiac survival after preemptive coronary angiography in transplant patients and those awaiting transplantation. Clin J Am Soc Nephrol. 2011;6(8):1912-1919. doi:10.2215/CJN.08680910

8. McFalls EO, Ward HB, Moritz TE, et al. Coronary-artery revascularization before elective major vascular surgery. $N$ Engl J Med. 2004;351(27):2795-2804. doi:10.1056/NEJMoa041905

9. Wijeysundera HC, Ko DT. Does percutaneous coronary intervention reduce mortality in patients with stable chronic angina: are we talking about apples and oranges? Circ Cardiovasc Qual Outcomes. 2009;2 (2):123-126. doi:10.1161/CIRCOUTCOMES.108.834853

10. Boden WE, O'Rourke RA, Teo KK, et al. Optimal medical therapy with or without PCI for stable coronary disease. $N$ Engl J Med. 2007;356(15):1503-1516. doi:10.1056/NEJMoa070829

11. Karthikeyan V, Ananthasubramaniam K. Coronary risk assessment and management options in chronic kidney disease patients prior to kidney transplantation. Curr Cardiol Rev. 2009;5(3):177-186. doi:10.2174/157340309788970342

12. Ojo AO, Hanson JA, Wolfe RA, Leichtman AB, Agodoa LY, Port FK. Long-term survival in renal transplant recipients with graft function. Kidney Int. 2000;57(1):307-313. doi:10.1046/j.15231755.2000.00816.x

13. Briggs JD. Causes of death after renal transplantation. Nephrol Dial Transplant. 2001;16(8):1545-1549. doi:10.1093/ndt/16.8.1545

14. Shah I, Faheem M, Hafizullah M. Clinical profile, angiographic characteristics and treatment recommendations in patients with coronary artery disease. J Pak Med Stud. 2013;3(2).

15. Agrawal V, Lohiya BV, Sihag BK, Prajapati R. Clinical profile with angiographic correlation in naïve acute coronary syndrome. J Clin Diagn Res. 2016;10(9):OC10.

16. Kumar N, Dahri L, Brown W, et al. Effect of elective coronary angiography on glomerular filtration rate in patients with advanced chronic kidney disease. Clin J Am Soc Nephrol. 2009;4(12):19071913. doi:10.2215/CJN.01480209

17. Ohtake T, Kobayashi S, Moriya H, et al. High prevalence of occult coronary artery stenosis in patients with chronic kidney disease at the initiation of renal replacement therapy: an angiographic examination. Clin J Am Soc Nephrol. 2005;16(4):1141-1148. doi:10.1681/ ASN.2004090765

18. Paizis IA, Mantzouratou PD, Tzanis GS, et al. Coronary artery disease in renal transplant recipients: an angiographic study. Hellenic J Cardiol. 2018. doi:10.1016/j.hjc.2018.07.002

19. Zhang Y, Pan Z, Fang J, Qu Q, Jiang X, Li M. Clinical effect of treating renal transplant recipients with percutaneous coronary intervention and its safety. Pak J Med Sci. 2016;32(2):333.

20. Kilickesmez KO, Abaci O, Okcun B, et al. Chronic kidney disease as a predictor of coronary lesion morphology. Angiology. 2010;61 (4):344-349. doi:10.1177/0003319709351875

21. Sharma R, Pellerin D, Gaze DC, et al. Dobutamine stress echocardiography and the resting but not exercise electrocardiograph predict severe coronary artery disease in renal transplant candidates. Nephrol Dial Transplant. 2005;20(10):2207-2214. doi:10.1093/ndt/gfi005

22. Herzog CA. How to manage the renal patient with coronary heart disease: the agony and the ecstasy of opinion-based medicine. Clin $J$ Am Soc Nephrol. 2003;14(10):2556-2572. doi:10.1097/01. ASN.0000087640.94746.47 
23. Pilmore H. Cardiac assessment for renal transplantation. Am J Transplant. 2006;6(4):659-665. doi:10.1111/j.1600-6143.2006.01253.x

24. Herzog CA, Marwick TH, Pheley AM, White CW, Rao VK, Dick CD. Dobutamine stress echocardiography for the detection of significant coronary artery disease in renal transplant candidates. $\mathrm{Am} \mathrm{J}$ Kidney Dis. 1999;33(6):1080-1090. doi:10.1016/S0272-6386(99) 70145-9

25. Enkiri SA, Taylor AM, Keeley EC, Lipson LC, Gimple LW, Ragosta M. Coronary angiography is a better predictor of mortality than noninvasive testing in patients evaluated for renal transplantation. Catheter Cardiovasc Interv. 2010;76(6):795-801. doi:10.1002/ ccd. 22656

26. Kodenchery M, Bhat S, El-Ghoroury M, Yamasaki H, McCullough PA. Coronary angiography before and after renal transplantation. Coronary Angiography-The Need for Improvement in Medical and Interventional Therapy. IntechOpen; 2011:147-158.

27. Workgroup KD. K/DOQI clinical practice guidelines for cardiovascular disease in dialysis patients. Am J Kidney Dis. 2005;45:S1-S153.

28. Danovitch GM, Hariharan S, Pirsch JD, et al. Management of the waiting list for cadaveric kidney transplants: report of a survey and recommendations by the clinical practice guidelines committee of the American Society of Transplantation. Clin J Am Soc Nephrol. 2002;13(2):528-535.

29. Fleisher LA, Fleischmann KE, Auerbach AD, et al. 2014 ACC/AHA guideline on perioperative cardiovascular evaluation and management of patients undergoing noncardiac surgery: a report of the American College of Cardiology/American Heart Association Task Force on practice guidelines. J Am Coll Cardiol. 2014;64(22):e77e137. doi:10.1016/j.jacc.2014.07.944

30. Charytan D, Mauri L, Agarwal A, Servoss S, Scirica B, Kuntz RE. The use of invasive cardiac procedures after acute myocardial infarction in long-term dialysis patients. Am Heart J. 2006;152(3):558564. doi:10.1016/j.ahj.2006.02.021

31. Chertow GM, Normand S-LT, McNeil BJ. "Renalism": inappropriately low rates of coronary angiography in elderly individuals with renal insufficiency. Clin J Am Soc Nephrol. 2004;15(9):2462-2468. doi:10.1097/01.ASN.0000135969.33773.0B
32. Lentine KL, Costa SP, Weir MR, et al. Cardiac disease evaluation and management among kidney and liver transplantation candidates: a scientific statement from the American Heart Association and the American College of Cardiology Foundation. J Am Coll Cardiol. 2012;60(5):434-480. doi:10.1016/j.jacc.2012.05.008

33. Charytan DM, Wallentin L, Lagerqvist B, et al. Early angiography in patients with chronic kidney disease: a collaborative systematic review. Clin J Am Soc Nephrol. 2009;4(6):1032-1043. doi:10.2215/ CJN.05551008

34. Blanca L, Jiménez T, Cabello M, Sola E, Gutierrez C, Burgos D, editors. Cardiovascular Risk in Recipients with Kidney Transplants from Expanded Criteria Donors. Transplantation Proceedings. Elsevier; 2012

35. Bax J, Van der Wall E. Assessment of Myocardial Viability: Guide to Prognosis and Clinical Management. Oxford University Press; 2000.

36. Volodarskiy A, Kumar S, Amin S, Bangalore S. Optimal treatment strategies in patients with chronic kidney disease and coronary artery disease. Am J Med. 2016;129(12):1288-1298. doi:10.1016/j. amjmed.2016.06.046

37. Bangalore S, Maron DJ, O'Brien SM, et al. Management of coronary disease in patients with advanced kidney disease. $N$ Engl $\mathrm{J} \mathrm{Med}$. 2020;382(17):1608-1618. doi:10.1056/NEJMoa1915925

38. Miller LW. Cardiovascular toxicities of immunosuppressive agents. Am J Transplant. 2002;2(9):807-818. doi:10.1034/j.16006143.2002.20902.x

39. Boots JM, Christiaans MH, van Hooff JP. Effect of immunosuppressive agents on long-term survival of renal transplant recipients. Drugs. 2004;64(18):2047-2073. doi:10.2165/00003495-20046418000004

40. Kleinsteuber A, Halleck F, Khadzhynov D, Staeck A, Lehner L, Duerr M, editors. Impact of Pre-Existing Comorbidities on LongTerm Outcomes in Kidney Transplant Recipients. Transplantation Proceedings. Elsevier; 2018
Transplant Research and Risk Management

\section{Publish your work in this journal}

Transplant Research and Risk Management is an international, peer-reviewed open access journal focusing on all aspects of transplantation and risk management to achieve optimal outcomes in the recipient improving survival and quality of life. The manuscript management system is completely online and includes a very quick and fair peer-review system, which is all easy to use. Visit http:/ www.dovepress.com/testimonials.php to read real quotes from published authors.

Submit your manuscript here: https://www.dovepress.com/transplant-research-and-risk-management-journal 